\title{
Estimation of serum creatinine in biochemistry department, Jigme Dorji Wangchuck National Referral Hospital, Thimphu, Bhutan
}

\author{
Sonam Chhoden $\mathrm{R}^{1}$, Kuenzang Chhenzom², Jigme Tenzin ${ }^{3}$ \\ ${ }_{1,2}^{1,2}$ Department of Biochemistry, Faculty of Postgraduate Medicine, Khesar Gyalpo University of Medical Sciences of Bhutan, Thimphu, Bhutan \\ ${ }^{3}$ Department of Pathology and Laboratory Medicine, Jigme Dorji Wangchuck National Referral Hospital, Thimphu, Bhutan
}

Creatinine produced endogenously is cleared from body by glomerular filtration at a constant rate. It is commonly estimated in plasma and serum to assess kidney function. Analytical methods such as chemical method and enzymatic method have been used to estimate the concentration in the biological fluid.

Chemical method was previously used in laboratory involved reaction of creatinine in the serum with alkaline picrate which produced a coloured complex. The difference in absorbance at 520 nanometers was measured.This change in absorbance was directly proportional to the concentration of the creatinine in the sample. Lack of specificity for creatinine has been a major drawback in this method.

Recently at JDWNRH, enzymatic method was introduced in the serum/plasma/urine estimation of creatinine which has high sensitivity $^{l}$. The enzymatic method employs usage of enzymes in the conversion of creatinine in our body to the final product quinone which is a reddish violet colour and the absorbance of this colour is measured. The colour intensity of the reaction is directly proportional to the concentration of creatinine in sample. This method is advantageous as it is more specific and is not affected by the interfering substance such as bilirubin upto $20 \mathrm{mg} / \mathrm{dl}$, haemoglobin upto $200 \mathrm{mg} / \mathrm{dl}^{2}$.

The reference interval for creatinine level varies slightly among the two analytical method as shown in Table $1-4^{3}$.

Table 1. Chemical Method: Jaffe and Enzymatic for serum creatinine values(adult)

\begin{tabular}{lll}
\hline \multirow{2}{*}{ Age } & \multicolumn{2}{c}{ Values (mg/dl) } \\
\cline { 2 - 3 } & $\begin{array}{l}\text { Chemical } \\
\text { method }\end{array}$ & $\begin{array}{l}\text { Enzymatic } \\
\text { method }\end{array}$ \\
\hline Adolescent & $0.5-1.0$ & \\
18-60 years (male) & $0.9-1.3$ & $0.62-1.10$ \\
$18-60$ years(female) & $0.6-1.1$ & $0.45-0.75$ \\
\hline
\end{tabular}

Table 2. Chemical method: Jaffe serum creatinine values (children)

\begin{tabular}{ll}
\hline Age group & Values (mg/dl) \\
\hline Cord blood & $0.6-1.2$ \\
Newborn (1-4 days) & $0.3-1.0$ \\
Infant & $0.2-0.4$ \\
child & $0.3-0.7$ \\
\hline
\end{tabular}

Table 3. Chemical method: Jaffe manual urine creatinine values

\begin{tabular}{ll}
\hline Age group & Values $(\mathbf{m g} / \mathbf{k g} / \mathbf{d})$ \\
\hline Infant & $8-20$ \\
Child & $8-22$ \\
Adolescent & $8-30$ \\
Adult (male) & $14-26$ \\
Adult(female) & $11-20$ \\
\hline
\end{tabular}

Table 4. Enzymatic method: serum creatinine values (children)

\begin{tabular}{ll}
\hline Age group & Values $(\mathbf{m g} / \mathbf{d l})$ \\
\hline 0-1 year & $0.04-0.33$ \\
2-5 years & $0.04-0.45$ \\
6-9 years & $0.20-0.52$ \\
10 years & $0.22-0.59$ \\
\hline
\end{tabular}

\section{Clinical usage}

Creatinine value is often used for diagnostic and disease monitoring purpose . According to the Kidney Disease Improving Global Outcome (KDIGO) acute kidney injury can be diagnosed using serum creatinine along with urine output. The diagnostic critera are as illustrated below ${ }^{4}$.

\section{Corresponding author: \\ Sonam Chhoden R \\ sonamcr@kgumsb.edu.bt}




\section{Diagnostic criteria for AKI according to KDIGO definition}

Increase in serum creatinine by $\geq 0.3 \mathrm{mg} / \mathrm{dl}$ within $48 \mathrm{hrs} \mathbf{O R}$

Increase in serum creatinine by $\geq 1.5$ times the baseline, which is known or presumed to have occurred within prior 7 days

OR

Urine volume $<0.5 \mathrm{ml} / \mathrm{kg} / \mathrm{h}$ for $6 \mathrm{hrs}$

$A K I$ acute kidney injury, $K D I G O$ Kidney Disease Improving Global Outcome

\section{REFERENCES}

1. Sagita O, Uchiyama K, Yamada T, Sato T, Okada M and Takeuchi K. Reference values of serum and urine creatinine, and of creatinine clearance by a new enzymatic method. Ann Clin Biochem 1992;29: 523-528. [Full Text]

2. Reagent leaflet (Pureauto S CRE-L) from Sekisui Medical Co. Ltd, Japan

3. Burtis, C.A,Ashwood, E.R, Bruns, D.E.C. Tietz fundamentals of clinical chemistry.(6th ed.).New Delhi: Elsevier; c2008 . [Full Text]

4. Ostermann M and Joannidis M Acute kidney injury 2016: diagnosis and diagnostic workup. Critical Care (2016) 20:299. [Full Text | DOI] 